\title{
O circuito finance-investimento-poupança- funding em economias abertas
}

MARCO FLÁVIO DA CUNHA RESENDE*

The finance-investment-savings-funding circuit in open economies. On monetary economies the Finance-Investment-Savings-Funding circuit (F-I-S-F) prevails. Investment precedes savings. This circuit was worked out for a closed economy. This study seeks to demonstrate that the circuit F-I-S-F also prevails for open economies. A second point studied in this paper relates the relationship between budget deficits and savings restriction for investment. Conclusions highlight that the circuit F-I-S-F prevails for open economies and that budget deficits do not cause savings restriction for investment. In some situations budget déficits transfer the effects of investment for national savings formation from domestic economy to the rest of the world.

Key-words: Finance-Investment-Savings-Funding, open economy, national saving.

JEL Classification: E12, E21, E62, F41.

\section{INTRODUÇÃO}

Em economias monetárias prevalece o circuito Finance-Investimento-Poupança-Funding. O investimento antecede a poupança que, por seu turno, resulta do crescimento econômico. O papel da poupança é consolidar (mas não financiar) a acumulação de capital, reduzindo a instabilidade financeira que acompanha o crescimento econômico e proporcionando sustentabilidade ao mesmo (Keynes, 1988b, 1988c; Davidson, 1992 e 1994; Minsky, 1986, Studart, 1995).

O circuito acima descrito foi originalmente formulado para o caso de economias fechadas. Ademais, parece não haver um estudo que considere este cir-

\footnotetext{
* Do Centro de Desenvolvimento e Planejamento Regional da Universidade Federal de Minas Gerais, e-mail resende@cedeplar.ufmg.br O autor agradece a Adriana M. Amado, Flavius M. L. Vasconcelos e a dois pareceristas anônimos pelos profícuos comentários referentes a uma versão preliminar deste estudo, eximindo-os de responsabilidade pelos erros e omissões porventura remanescentes. Submetido: Fevereiro 2006; aceito: Agosto 2006.
} 
cuito e seus mecanismos em economias abertas. Portanto, este trabalho visa avaliar se as características do citado circuito permanecem válidas para economias abertas, em especial se o investimento continua precedendo a poupança após a abertura da economia monetária.

No âmbito do debate sobre a precedência do investimento em relação à poupança, uma segunda questão também não é consensual: trata-se do argumento referente à insuficiência de poupança nacional em relação ao investimento, provocada por um déficit público. Este argumento não seria válido no referencial teórico pós-keynesiano, pois não pode haver insuficiência (ou restrição) de poupança em relação ao investimento se é este que precede aquela. Pretende-se, também neste trabalho, abordar este ponto a partir do conhecimento da relação entre déficit público e formação da poupança nacional no contexto do circuito Finance-Investimento-Poupança-Funding.

Além desta introdução o artigo conta com outras 4 seções. Na seção 2 explicita-se a relação de causalidade do investimento para a poupança no âmbito do circuito pós-keynesiano finance-investimento-poupança-funding de uma economia fechada. Em seguida, demonstra-se a validade deste circuito para economias abertas. Na seção 4 discute-se a relação entre déficit público, investimento e formação da poupança nacional no âmbito do circuito finance-investimento-poupança-funding em economias abertas. A seção 5 destina-se às conclusões do trabalho.

\section{O CIRCUITO FINANCE-INVESTIMENTO-POUPANÇA-FUNDING NA ECONOMIA FECHADA}

O financiamento do investimento elaborado em Keynes (1988c) apresenta duas etapas: i) o investimento planejado, quando a poupança ainda não foi criada via multiplicador ${ }^{1}$ esse investimento corresponde ao crédito de curto prazo demandado pelas firmas no intervalo de tempo entre a decisão de investimento e sua implementação, visando financiar a produção de bens de capital. Essa demanda de crédito foi denominada por Keynes de finance motive; ii) o investimento propriamente dito, ao qual corresponde uma poupança agregada que surge via multiplicador dos gastos.

O financiamento de curto prazo está ligado a um "fundo rotativo". ${ }^{2} \mathrm{O}$ crédito associado ao finance encontra sua oferta nesse fundo. Ele é usado para estimular a atividade na indústria de bens de investimento, gerando, neste processo, uma renda através do multiplicador keynesiano. ${ }^{3}$ Parte desta renda retorna ao

\footnotetext{
1 "O investimento planejado - isto é, o investimento ex ante - pode precisar garantir sua provisão financeira antes que ocorra o investimento, quer dizer, antes que a poupança correspondente se processe". Keynes (1988b:322).

${ }^{2}$ Detalhes em Keynes (1988c).
} 
sistema financeiro visto que não é usada para consumo, constituindo-se em poupança. Ao final desse processo, a poupança, resultante da despesa de investimento, é usada para transformar a dívida de curto prazo dos investidores junto ao sistema bancário em passivo de longo prazo. O funding corresponde a esse processo de "consolidar" a dívida de curto prazo, isto é, transformá-la numa relação de longo prazo através da emissão de ações e de títulos. ${ }^{4}$ Assim, poupança e financiamento da despesa do investimento não se confundem, necessariamente. ${ }^{5}$

A taxa de juros, por sua vez, não depende da poupança, pois se constitui num fenômeno monetário e se relaciona inversamente com o investimento. Na economia monetária, a taxa de juros não é a retribuição "pela espera para consumir" e, sim, pela renúncia à liquidez. $\mathrm{O}$ juro é determinado pela preferência pela liquidez e pela oferta de moeda, esta última determinada pela política monetária e pelas estratégias de crédito dos bancos. ${ }^{6} \mathrm{O}$ conceito de preferência pela liquidez está associado ao conceito de incerteza. ${ }^{7}$ Ademais, o investimento é sensível ao grau de incerteza e às expectativas a ele associadas, que, por seu turno, dependem das condições de finance e de funding do sistema, entre outros fatores. ${ }^{8}$

\footnotetext{
3 "Empresários devem ter os saldos monetários em mãos entre os períodos de pagamento relativo aos contratos de compra de insumos requeridos para a produção de bens de capital de modo a assegurarse de que estão aptos a cumprir esses contratos. A quantidade de saldos monetários necessária em cada período para fazer face a esses contratos (pagamentos) futuros ligados à produção de bens de investimento permanecerá inalterada enquanto o investimento planejado também permanecer. Se, por exemplo, as expectativas de lucro crescerem exogenamente, (...) empresários demandarão bens de investimento adicionais (...) a demanda por moeda para pagar pela produção desses bens de investimento adicionais a qualquer nível de taxa de juros crescerá mesmo antes de qualquer emprego e renda adicionais terem sido gerados (...) é evidente do Tratado sobre a Moeda e das notas de Keynes de 1937 (...) sobre o motivo finanças, que, especificar a demanda por moeda como uma função direta da renda corrente é uma simplificação grosseira e errada de sua análise da liquidez." Davidson (1994:122-123). Ainda "Investimento é um processo no tempo e envolve um grande número de firmas que produzem insumos para a formação do ativo de capital final. Investimento envolve um complexo de pagamentos que precisa ser financiado (...) investimento em nossa economia é uma transação de troca de dinheiro agora por dinheiro mais tarde." Minsky (1986:214).

${ }^{4}$ Note, neste processo, a relevância da defasagem temporal existente entre o pedido feito à indústria de bens de capital, que corresponde à decisão de investir, e a maturação da produção dessa categoria de bens. Note, também, a relevância dos mercados secundários, visto que estes garantem liquidez para títulos de longo prazo. É a possibilidade de se desfazer desses títulos no curto prazo, por meio de suas vendas nos mercados secundários, que os tornam atrativos para os poupadores. Este seria o lado positivo, desses mercados. O lado negativo corresponde à sua natureza especulativa, que pode provocar uma redução nos preços dos títulos (dado um aumento da preferência ela liquidez), em geral, deteriorando o nível de fragilidade financeira de todo o sistema econômico (Minsky, 1986).

5 "Mas 'financiamento' nada tem a ver com poupança (...) 'Financiamento' e 'compromissos de financiamento' são simples entradas contábeis de crédito e débito, que facilitam aos empresários ir adiante com segurança". Keynes (1988b:323).

${ }^{6}$ Sobre o comportamento da firma bancária em economias monetárias, ver, por exemplo, Minsky (1986, 1992) e De Paula (1999).

${ }^{7}$ Sobre o caráter endógeno da oferta de moeda, ver Davidson (1994:135-136) e Carvalho (1993). Sobre o conceito de incerteza, ver Amado (2000) e Carvalho (1992,a,b).

${ }^{8}$ Conforme Keynes (1988a:101),“O leitor notará que a eficiência marginal do capital é definida aqui em termos da expectativa da renda e do preço de oferta corrente do bem de capital. Ela depende da
} 
Este modus operandis da economia monetária de produção verifica-se porque nesta economia as concepções de moeda, de tempo e de incerteza são fundamentais. Estas concepções rompem com os axiomas neoclássicos e introduzem novos fundamentos para a economia monetária, invalidando a teoria neoclássica, conforme demonstram Carvalho (1992a,b), Amado (2000), Davidson (1992). Deste modo, em economias monetárias prevalece o circuito Finance-Investimento-Poupança-Funding (F-I-S-F). O investimento antecede a poupança que, por seu turno, resulta do crescimento econômico e se presta à consolidação da acumulação de capital. O circuito acima descrito foi originalmente formulado para o caso de economias fechadas. Na próxima seção avalia-se se esse circuito permanece válido para economias abertas.

\section{O CIRCUITO FINANCE-INVESTIMENTO-POUPANÇA-FUNDING NA ECONOMIA ABERTA}

O circuito F-I-S-F para uma economia fechada está representado no fluxograma 1 , onde BCS = bens de consumo e BK = bens de capital. Na economia fechada o circuito é caracterizado pela realização do finance, seguida da compra de BK e da geração de renda (inicial) no setor produtor desta categoria de bens. Parcela desta renda é então usada para consumo e o restante constitui-se em poupança no âmbito do processo multiplicador dos gastos. Ao final desse processo tem-se a poupança necessária para a realização do funding, completando-se o circuito F-I-S-F.

Fluxograma 1: Finance-Investimento-Poupança-Funding em Economias Fechadas

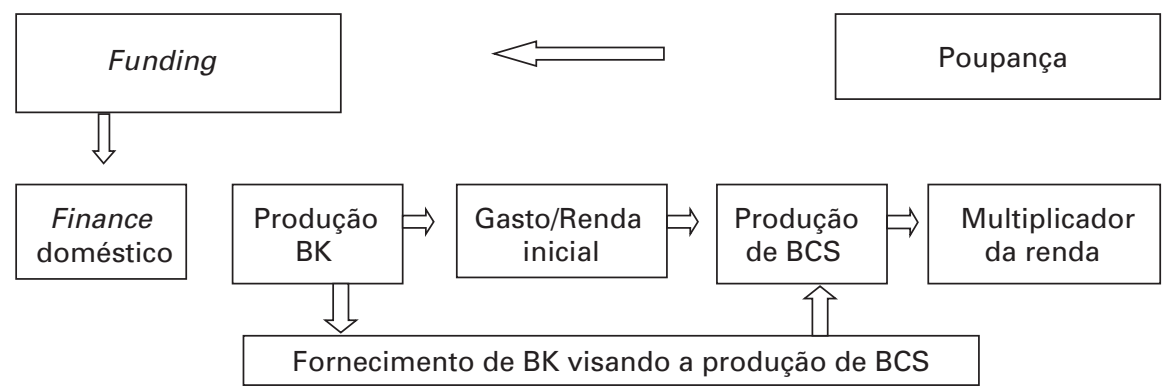

taxa de retorno que se espera obter do dinheiro investido num bem recentemente produzido; e não do resultado histórico obtido por um investimento em relação a seu custo original, quando examinado retrospectivamente ao fim de sua vida." (grifos nosso). Sobre grau de incerteza em economias monetárias, ver Crocco (2002). 
$\mathrm{Na}$ economia aberta estas mesmas etapas são necessárias para o funcionamento do circuito, porém, a participação do sistema financeiro internacional torna-se imprescindível para a realização do mesmo. Deste modo, para o caso de economias abertas, o sistema financeiro internacional e o comércio internacional fazem parte do circuito F-I-S-F, além das categorias presentes no caso da economia fechada. As principais inter-relações que se formam no âmbito do circuito FI-S-F com economias abertas estão descritas a seguir.

A partir do finance realizado através da captação de recursos no sistema financeiro internacional verifica-se a importação de BK. De outro lado, o finance realizado no sistema financeiro doméstico destina-se à produção doméstica de BK. Estes BK, produzidos internamente ou importados, serão exportados ou serão usados para produzir BCS que, por seu turno, destinam-se ao mercado externo. As exportações de BK ou de BCS geram a renda (inicial) que detonará o processo multiplicador de gastos. A poupança surge como resíduo ao final deste processo e é utilizada para a realização do funding, completando-se o circuito.

Portanto, em um mundo onde as economias são abertas, a concretização das importações e das exportações no âmbito do circuito F-I-S-F, como também a realização da primeira etapa deste circuito, isto é, do finance, tem como requisito fundamental a participação do sistema financeiro internacional.

Porém, visando alcançar maior detalhamento dos mecanismos que se formam no interior do circuito F-I-S-F para economias abertas, será apresentado nas próximas sub-seções o estudo de dois casos. Ademais, o estudo desses casos é relevante para a construção do argumento referente à precedência do investimento em relação à poupança em economias abertas. Para demonstrar a possibilidade de verificação deste argumento não é necessário que se esgote todos os casos possíveis. Para demonstrar a validade do argumento, basta que se apresente uma situação concreta onde o investimento precede a poupança. ${ }^{9}$ Deste modo, serão estudadas a seguir duas situações para economias abertas. Na Situação 1, as economias apresentam equilíbrio no balanço de transações correntes. $\mathrm{Na}$ Situação 2, os balanços de transações correntes são superavitários ou deficitários.

\section{O caso de economias com equilíbrio em transações correntes}

Nesta subseção será estudada a Situação 1: suponha duas economias, W e $\mathrm{Z}$, ambas produzindo bens de consumo (BCS) e bens de capital (BK) e operando a pleno emprego dos fatores. ${ }^{10}$ Parcela da produção de BK da economia W será exportada para Z, enquanto parcela da produção de BCS desta última será exportada para $\mathrm{W}$. A exportação de BCS de $\mathrm{Z}$ possui o mesmo valor em moeda es-

\footnotetext{
${ }^{9}$ Isto não quer dizer que a situação inversa, onde a poupança antecede o investimento, não seja, também, válida.

${ }^{10} \mathrm{O}$ pleno emprego corresponde ao uso de toda a capacidade instalada de produção, mas considerase que a oferta de trabalho seja elástica.
} 
trangeira da exportação de $\mathrm{BK}$ de $\mathrm{W}$ - ambas as economias apresentam saldo em conta corrente equilibrado.

No país W, a produção de BK a ser exportada segue o circuito F-I-S-F de acordo com o modelo da economia fechada, numa primeira etapa. Há inicialmente o finance para a produção de BK gerando renda (inicial). Porém, esta será integralmente usada para importar BCS de Z. Assim, não haverá o surgimento de um consumo induzido pela renda inicial, gerada a partir dos gastos realizados no processo de produção de $\mathrm{BK}$, e, portanto, não haverá a poupança associada a este processo. ${ }^{11}$ Entretanto, os BK produzidos são exportados, proporcionando os recursos necessários para o funding do investimento no país W. Neste país, os recursos externos obtidos com a exportação de BK, como também a renda gerada na produção desses bens, são integralmente usados na importação de BCS de $Z$, ensejando o equilíbrio em suas transações com o exterior (Fluxograma 2).

Fluxograma 2: Situação 1 - País W

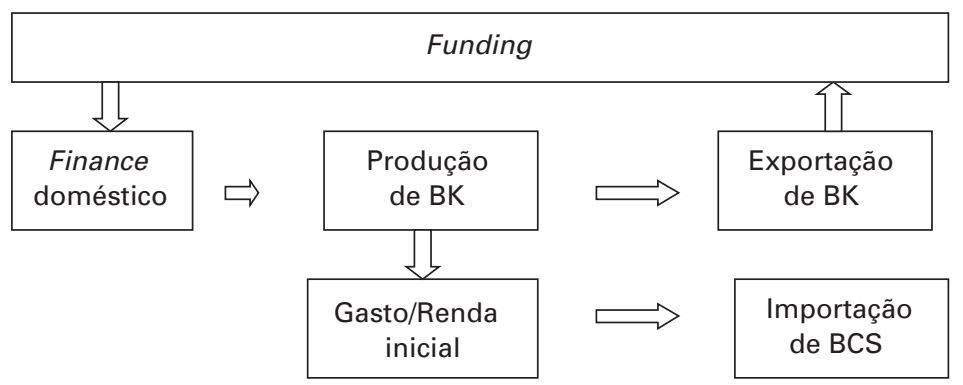

Exportação (líquida) de BK = Importação (líquida) de BCS

No país Z, houve inicialmente o circuito finance-investimento-poupançafunding, produzindo-se BK e BCS. A economia está fechada, num primeiro momento, se comportando conforme descrito em Keynes (1988b,c). Decide-se, então, produzir BCS para exportação, o que torna necessária a importação de BK, pois há pleno emprego dos fatores no país Z. Mediante finance realizado no mercado internacional obtém-se os recursos em moeda estrangeira requeridos para importar BK. Após a importação de BK, são produzidos BCS, cuja exportação enseja, ao mesmo tempo, recursos em moeda estrangeira e a renda inicial (gerada a partir dos gastos dos estrangeiros com os BCS exportados e que se traduzem em renda dos fatores usados na produção desses BCS) que induz um consumo interno e, via efeito multiplicador, gera poupança. Essa poupança constitui o funding da dívida externa de curto/médio prazo, fruto do finance realizado no mercado internacional visando a importação de BK pelo país W. Ou seja, supondo que os BK importados se depreciam totalmente em um único período, então a

\footnotetext{
${ }^{11}$ A hipótese de que a renda gerada na produção de BK é integralmente (ao invés de parcialmente) usada para importar BCS facilita a exposição sem comprometer os resultados.

${ }^{12}$ Esta hipótese simplificadora facilita a exposição sem comprometer as conclusões.
} 
poupança surgida neste processo é da mesma magnitude não apenas das exportações de BCS, mas, também, das importações de BK. ${ }^{12}$ Assim, a poupança gerada no processo de produção dos BCS destinados ao mercado externo tem como contrapartida a exportação destes bens, cujos recursos, em divisas estrangeirais, se destinam ao funding do investimento associado à anterior importação de BK. No país $\mathrm{Z}$ a importação de BK impôs a necessidade de um finance externo, que foi "consolidado" a partir dos recursos originados pela sua exportação de BCS (poupança nacional) - Fluxograma 3.

Fluxograma 3: Situação 1 - País Z

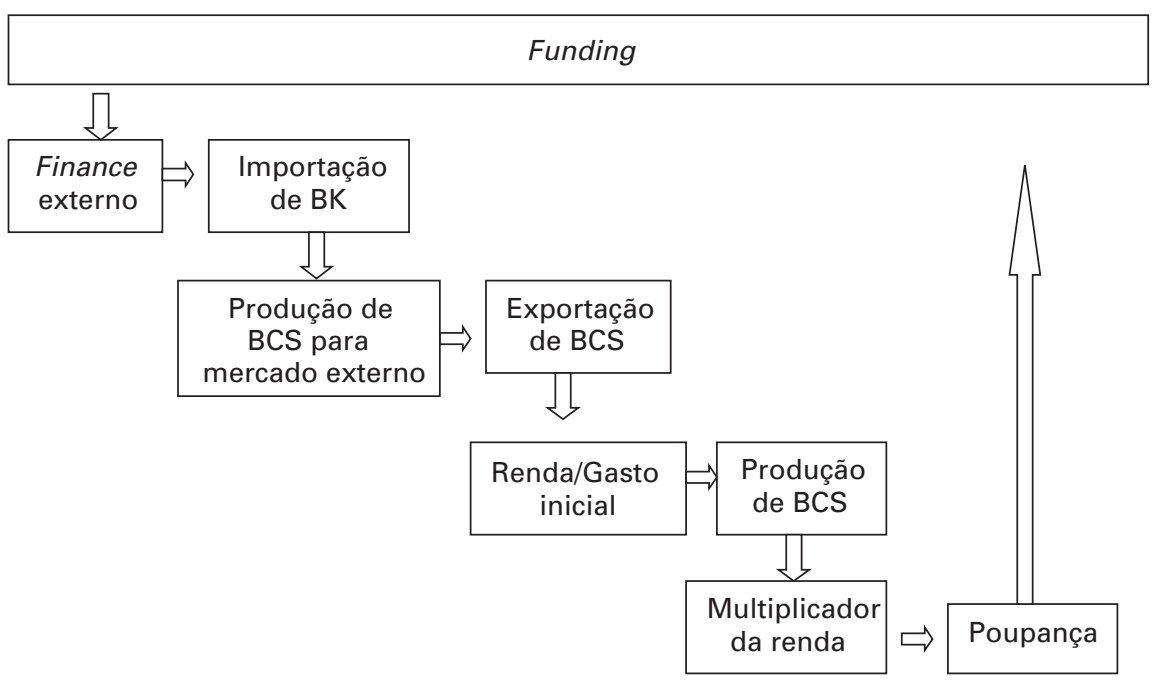

Investimento $=$ Importação (líquida) de BK $=$ Exportação (líquida) de BCS = Poupança

As transações das economias W e Z ficam, então, equilibradas. No país W, o investimento pode ocorrer sem a necessidade de poupança prévia, mas a renda gerada na produção de BK não é usada para adquirir BCS domésticos e, sim, os bens importados de Z. Ou seja, após ocorrer o investimento no país W não há um crescimento da renda via multiplicador que irá gerar a poupança necessária para o funding associado à produção de BK, visto que houve um "vazamento" da renda (importações). A própria exportação de BK gera os recursos necessários para a liquidação do finance que originou esse investimento.

De outro lado, a renda gerada na produção de BK em W será usada para importar BCS de Z, e, então, gerar neste outro país os recursos em moeda estrangeira necessários para realizar o funding associado ao finance externo usado por $\mathrm{Z}$ para importar os BK de W. Assim, o investimento verificado em $\mathrm{Z}$ corresponde à importação de BK, realizada a partir do finance externo e não de uma poupança prévia. Essa importação de BK destina-se à produção de BCS para exportação. A poupança é gerada em $\mathrm{Z}$ via multiplicador da renda que, por sua vez, 
origina-se da renda inicial gerada na produção e exportação de BCS. De outro lado, o finance externo contratado por Z corresponderá à importação de BK, gerando em $\mathrm{W}$ os recursos necessários para o funding do seu investimento. É possível, ainda, um segundo cenário, onde há desequilíbrio na balança comercial de W e de Z.

\section{O Caso de Economias com Desequilíbrio em Transações Correntes.}

Nesta subseção será estudada a Situação 2: suponha que o país W exporte BK para Z e que este país não exporte nada para W. O circuito F-I-S-F verificado em W é o mesmo daquele correspondente à economia fechada, a não ser pelo fato de que parcela da produção doméstica de BK não se destina ao mercado interno, sendo exportada. Neste caso, o consumo (real) induzido pela renda gerada na produção dos BK exportados, como também a expansão do produto real associada a este processo, só ocorrerá se o nível inicial do produto estiver aquém do nível de pleno emprego - há capacidade ociosa na indústria de BCS do país W de modo que esta pode prescindir dos BK exportados para aumentar sua produção. ${ }^{13}$

A renda inicial gerada na produção dos BK destinados à exportação induz o consumo interno e, via efeito multiplicador, a poupança surge como resíduo. Nesse processo, a renda não consumida corresponde à poupança cuja contrapartida são exportações de BK, isto é, superávit em conta corrente. A poupança proporciona os recursos financeiros necessários ao funding relacionado à produção de BK e, paralelamente, as exportações desses bens enseja um aumento das reservas externas do país W, que podem ser usadas como oferta de crédito deste país à economia Z - visando o financiamento das importações de BK desta - contribuindo para reduzir a vulnerabilidade da inserção internacional de W (Fluxograma 4).

Em Z, há pleno emprego dos fatores e o saldo em conta corrente está equilibrado. Uma nova importação de BK produzirá um déficit em conta corrente. $\mathrm{O}$ finance externo usado para importar os BK não é consolidado na ausência das exportações de BCS. Contudo, o restante do circuito finance-investimento-poupança-funding é semelhante àquele observado na economia fechada. Os BK importados são usados para produzir outros BK e há, para isso, um finance interno. Neste processo, a renda cresce e a poupança que consolidará o finance interno surge como resíduo. Em Z, o balanço de pagamentos permanece equilibrado no curto prazo, visto que às importações de BK correspondeu uma entrada de recursos externos pela Conta Financeira do balanço de pagamentos. Contudo, a economia $\mathrm{Z}$ passa a carregar um passivo externo, aumentando a vulnerabilidade de sua inserção internacional (Fluxograma 5).

\footnotetext{
${ }^{13}$ Esta hipótese pode ser relaxada quando a economia opera a pleno emprego, porém, uma depreciação da taxa de câmbio real amplia sua produção potencial de bens comerciáveis, conforme será analisado na seção 4 .
} 
Fluxograma 4: Situação 2 - País W

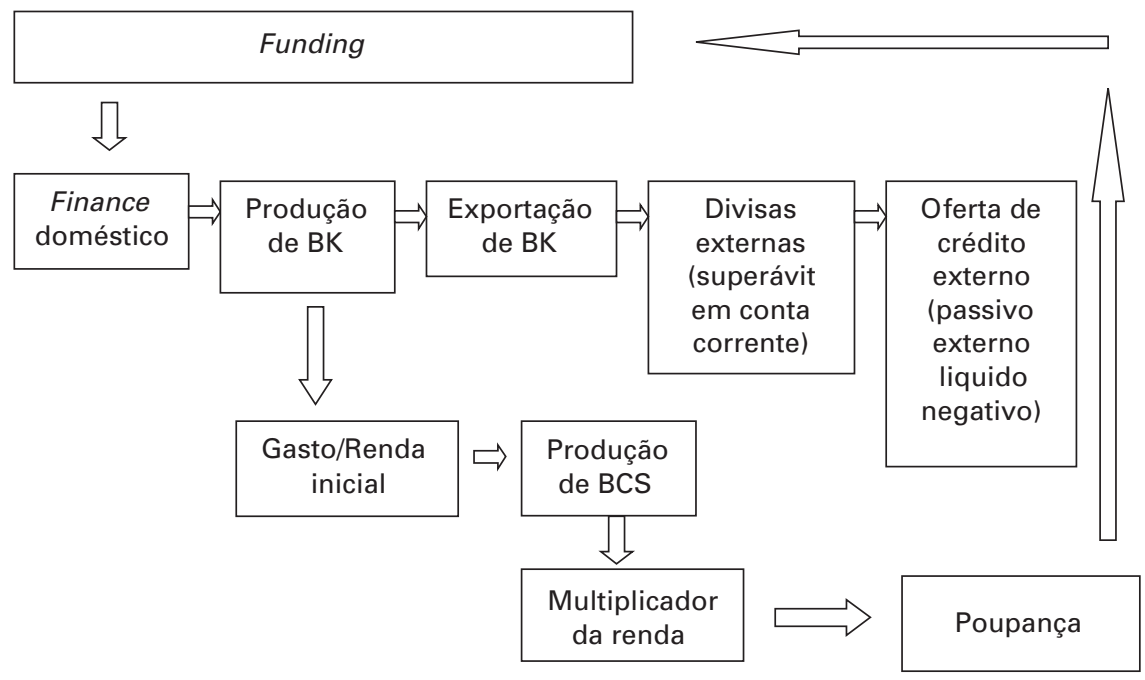

Exportação (líquida) de BK = Poupança $=$ Superávit em conta corrente

Fluxograma 5: Situação 2 - País Z

Finance
externo $\Rightarrow \begin{gathered}\text { Importação } \\ \text { de BK }\end{gathered} \Rightarrow \begin{gathered}\text { Déficit em } \\ \text { conta corrente }\end{gathered} \Rightarrow \begin{gathered}\text { Passivo externo } \\ \text { líquido }\end{gathered}$

Investimento $=$ Importação (líquida) de BK = déficit em conta corrente

Portanto, a precedência do investimento em relação à poupança permanece válida em economias abertas e em situação de (des)equilíbrio comercial, enquanto o circuito F-I-S-F é mais complexo e requer a participação dos mercados financeiros domésticos e internacionais. As relações débito-crédito são ampliadas, como também o são a coordenação dessas relações e a incerteza envolvida nesse processo, que, inclusive, engloba a possibilidade de mudanças na taxa de câmbio, conforme Davidson (1992:83-140; 1994:223-237). ${ }^{14}$

No caso do país Z, tanto na Situação 1 como na Situação 2 o finance iniciase no mercado internacional. Na Situação 1 , a moeda estrangeira percorre o seguinte circuito: há um finance no mercado internacional realizado por $\mathrm{Z}$ visando a importação de BK para a produção de BCS destinados ao mercado externo. A importação desses BK gera em $\mathrm{W}$ os recursos em moeda estrangeira que serão utilizados para importar BCS de Z. Ao obter esses recursos a economia Z liquida o finance que realizou no mercado internacional visando a importação de BK.

\footnotetext{
${ }^{14}$ Ademais, se as possibilidades de os empresários verem frustradas suas expectativas aumentam com a abertura da economia, elas se elevam ainda mais quando as trocas internacionais são feitas entre economias com graus diferentes de desenvolvimento. Sobre este ponto, ver Resende (2003).
} 
Na Situação 2, a moeda estrangeira percorre o seguinte circuito: há um finance no mercado internacional realizado por $\mathrm{Z}$ visando a importação de BK para, em última instância, produzir BCS destinados ao mercado doméstico. De outro lado, os recursos em moeda estrangeira obtidos por W a partir de sua exportação de BK correspondem ao crédito externo demandado por $\mathrm{Z}$. Com esses recursos a economia $\mathrm{Z}$ liquida o finance que realizou no mercado internacional, mas sua dívida com $\mathrm{W}$ permanece ativa. Assim, o passivo externo líquido de $\mathrm{Z}$ aumenta enquanto o de $\mathrm{W}$ se reduz.

\section{INVESTIMENTO, POUPANÇA E TAXA DE CÂMBIO REAL NO CIRCUITO F-I-S-F}

A precedência do investimento em relação à poupança não é consensual na literatura econômica. No contexto desse debate há uma segunda questão sobre a qual também não há consenso: trata-se da insuficiência de poupança nacional em relação ao investimento, provocada por um déficit público. Em equilíbrio macroeconômico (ex post), o investimento é contabilmente igual à soma das poupanças nacional e externa (Feijó et alli, 2001:8). A poupança nacional é a renda não consumida e está associada à produção doméstica de capital. Portanto, argumenta-se que o déficit público estaria associado ao aumento do consumo para um dado nível do produto, o que resultaria em redução da taxa de poupança nacional. Conseqüentemente surgiria uma insuficiência de poupança nacional para um dado nível de investimento (Resende, 1995), o que poderia ser expresso como uma restrição ao crescimento econômico. A manutenção do nível do investimento requeriria, então, absorção de poupança externa, implicando déficit em transações correntes. Este argumento é também conhecido coma a tese dos déficits gêmeos. ${ }^{15}$

Conforme Giambiagi \& Amadeo (1990), a restrição de poupança ao investimento (decorrente do déficit público) só se verifica quando o nível do produto corresponde ao nível de pleno emprego. Neste caso, não haveria recursos reais disponíveis que permitissem absorver um aumento do gasto público (líquido). Segundo estes autores, tal absorção só seria possível mediante uma redução do consumo e/ou do investimento.

Todavia, Giambiagi \& Amadeo (1990) cometem dois equívocos que comprometem suas conclusões. Segundo estes autores, há três restrições relacionadas ao crescimento: restrição de poupança, restrição externa e restrição de demanda. Porém, para demonstrar a restrição de poupança, eles assumem uma relação de

\footnotetext{
${ }^{15}$ Ver, por exemplo, Baharumshah et alli (2005), Winckler et alli (1999), Vamvoukas (1999), Krugman (1992), Feldstein (1992), Rosensweig e Tallman (1993), Oskooee (1995), Giambiagi \& Amadeo (1990).
} 
causalidade entre poupança e investimento (equação 12 de Giambiagi \& Amadeo, 1990), onde este seria função da poupança, a partir de uma identidade contábil (equação 11 de Giambiagi \& Amadeo, 1990), embora eles próprios tivessem argumentado anteriormente que: i) o investimento causa a poupança, e, não, o contrário; ii) identidades contábeis não apontam uma relação de causalidade. Ambos os pontos estão amparados nas seguintes passagens:

"o discutido até aqui nada mais é que uma apresentação de equações contábeis. Estas nada nos dizem, porém, sobre as relações de causalidade envolvidas na análise. Por isso, é fundamental ir além das identidades (...) A forma como o tema costuma ser tratado na literatura parece-nos responsável pela confusão analítica associada à relação entre poupança e investimento. As análises feitas a posteriori supõem que o aumento do investimento é causado pelo crescimento da poupança, ou que o investimento não atingiu o nível satisfatório porque a poupança foi insuficiente. O que essas análises não levam em consideração é que a decisão dos indivíduos de poupar uma parcela maior dos seus rendimentos não necessariamente irá se transformar num aumento do investimento e da poupança agregados, ao passo que um aumento do investimento implica necessariamente a geração de um fluxo de poupança de igual valor [...]" Giambiagi \& Amadeo (1990:82).

Ainda,

“Em particular, a relação de causalidade apontada por Keynes, do investimento para a poupança - contrariamente à visão neoclássica continua válida sob qualquer hipótese, acerca das circunstâncias vigentes (...) embora em condições de pleno emprego keynesianos e neoclássicos concordem quanto ao possível excesso de consumo (...) uma leitura neoclássica dos fatos conduzirá à recomendação de aumentar a poupança, ao passo que uma interpretação keynesiana dos fatos levará a concluir que é preciso investir mais. A diferença entre ambas as recomendações, imperceptível quando se lida apenas com identidades contábeis, sem discutir a teoria que figura por trás das mesmas, é crucial [...]" Giambiagi \& Amadeo (1990:78).

Por fim,

"pode-se argumentar que reduzir o consumo e aumentar a poupança, se ocorrer um aumento do investimento, correspondem ao mesmo fenômeno. Entretanto, a seqüência lógica é diferente, ou seja, na prática o que ocorre não é que a queda do consumo gera um aumento da poupança e este uma elevação do investimento e, sim, que o aumento do investimento acarreta um aumento da poupança e, em condições de 
pleno emprego, exige uma redução do consumo" Giambiagi \& Amadeo (1990:82). Grifo nosso.

Portanto, os autores argumentam que no pleno emprego a redução do consumo permitira o aumento do investimento e, em seguida, a poupança também cresceria como conseqüência deste. Ora, reduzir o consumo para uma dada renda significa ampliar a poupança antes mesmo que o investimento ocorra, pois poupança é, por definição, a renda não consumida. Ademais, há neste argumento a hipótese de que bens de capital que produzem bens de consumo podem se metamorfosear em produtores de bens de capital já que Giambiagi \& Amadeo (1990) não trabalham com a taxa de câmbio real em seu modelo. ${ }^{16}$

Aliás, tal hipótese de metamorfose dos bens de capital foi feita explicitamente através de exemplo capcioso apresentado em Giambiagi (1988:12): ele supõe que, a pleno emprego, a redução do consumo de automóveis (bem de consumo) permitiria o aumento da produção de caminhões (bem de capital). Porém, neste caso particular os mesmos bens de capital que produzem bens de consumo (autmóveis) podem, em geral, produzir também um tipo específico de bens de capital, a saber, caminhões. Mas esta versatilidade dos BK é uma exceção, não a regra.

Do mesmo modo, para demonstrar a restrição externa ao crescimento, os autores, partindo da mesma identidade contábil, assumem que "[...] um aumento da taxa de poupança interna pode se traduzir no crescimento das exportações e, conseqüentemente, das importações e do investimento" Giambiagi \& Amadeo (1990:85). Novamente os autores se contradizem, pois nesta passagem a poupança antecede o investimento. Além disso, a identidade contábil não aponta para uma relação de causalidade entre poupança e exportação e, então, novamente a demonstração dos autores não é válida (equação 20$){ }^{17}$

A tese dos déficits gêmeos contradiz a abordagem pós-keynesiana. Nesta abordagem a restrição ao crescimento econômico não poderia ser de poupança visto que é o investimento que antecede a poupança e, não, o inverso. Resende (2005) baseia-se em Tavares et alli (1982:35) para argumentar que tal tese não

\footnotetext{
${ }^{16}$ Este ponto ficará claro logo a seguir.

${ }^{17}$ Por fim, a relação apresentada no Gráfico 3 de Giambiagi e Amadeo (1990:86), a saber, um aumento da propensão a poupar eleva o investimento, também não é válida e expressa a contradição destes autores que consideram correta a proposição de Keynes de que a poupança resulta do investimento, e não o inverso. A propensão interna a poupar, si, não afeta o investimento. Tal propensão, que é o inverso da propensão a consumir, determina apenas o número de etapas do circuito gastorenda-poupança inserido no processo multiplicador da renda e detonado pelo investimento. Após ter se verificado o investimento, a poupança será sempre a mesma, sendo ao final do processo multiplicador igual ao investimento, ou seja, se a propensão a poupar cresce, então haverá um menor número de etapas no circuito gasto-renda-poupança, de modo que, para cada nível do investimento, a poupança será a mesma ao final do processo, seja qual for o tamanho de si. Deste modo, o investimento inicial não é afetado pelo tamanho de $s i$, mas, apenas, o número de etapas associadas ao multiplicador dos gastos é afetado.
} 
seria válida para uma economia fechada uma vez que em certo momento do tempo o estoque de capital da economia está dado. Assim, "o aumento da absorção doméstica não pode transformar bens de capital destinados à produção de capital em bens de capital destinados à produção de bens de consumo, e vice-versa" Resende (2005:04). Neste caso, o déficit público não reduz a disponibilidade interna de máquinas e equipamentos requeridos para o investimento e, então, seriam falaciosas as relações entre déficit público e insuficiência de poupança nacional e entre déficit público e déficit externo.

Contudo, este mesmo autor considera que o argumento de Tavares et alli (1982) só é válido para economias fechadas. Em economias abertas, mudanças na taxa de câmbio real afetam a poupança nacional. Deste modo, quando o déficit público afeta os preços relativos da economia, a oferta de bens de investimento e a poupança nacional também se alteram. ${ }^{18}$

Uma depreciação da taxa de câmbio real corresponde a um aumento dos preços dos bens comerciáveis em relação aos preços dos bens não comerciáveis. Conforme Pastore \& Pinotti (1995:141), o aumento relativo dos preços dos bens comerciáveis estimula a substituição do consumo em direção aos não-comerciáveis, ao mesmo tempo em que estimula o aumento da produção daqueles. Do mesmo modo, a apreciação da taxa de câmbio real estimula a substituição do consumo em direção aos bens comerciáveis ao mesmo tempo em que inibe sua produção. Assim,

"O aumento dos preços dos BC (bens comerciáveis) em relação aos preços dos BNC (bens não comerciáveis) resulta, então, em aumento do saldo comercial. A elevação das exportações líquidas corresponde contabilmente à ampliação da poupança nacional. Portanto, máquinas que produzem bens de consumo não podem se metamorfosear em máquinas produtoras de bens de investimento, porém, os bens de consumo exportados geram divisas externas para importar bens de capital.” Resende $(2005: 5)$.

Portanto, é através de alterações nos preços relativos que o déficit público pode inibir a poupança nacional. Quando o déficit público causa apreciação da taxa de câmbio real a poupança se reduz. Resende (2005) estudou a relação entre déficit público e taxa de câmbio real e concluiu que,

“[...] mesmo supondo ausência de crowding out e de Equivalência Ricardiana, não há uma relação sistemática entre déficit público e apre-

\footnotetext{
${ }^{18}$ Embora não demonstre os mecanismos através dos quais o aumento da absorção doméstica sobre a produção nacional pode afetar a taxa de câmbio real, Krugman (1992) também argumenta que o déficit público só causa o déficit externo por meio da mudança de preços relativos.
} 
ciação da taxa de câmbio real. No regime de taxa de câmbio fixa, tal relação é válida apenas quando a economia opera a pleno emprego. ${ }^{19}$ No regime de taxa cambial flexível, em nenhuma das situações estudadas esta relação verifica-se, necessariamente.” Resende (2005:7).

Todavia, mesmo quando o déficit púbico leva a uma apreciação cambial e, conseqüentemente, a uma redução da poupança nacional, na abordagem póskeynesiana não pode haver restrição de poupança ao investimento já que aquela não antecede este, necessariamente. Ademais, na economia fechada o investimento é sempre igual à poupança nacional, enquanto na economia aberta o investimento é sempre igual à soma da poupança nacional e da absorção de poupança externa (déficit em transações correntes do balanço de pagamentos).

Portanto, qual é a relação entre déficit público, investimento e poupança em economias monetárias abertas? Quando o déficit público implica apreciação da taxa de câmbio real, parcela da demanda de investimentos é deslocada para o exterior, afetando a taxa de poupança nacional. ${ }^{20} \mathrm{O}$ aumento do preço relativo dos bens não comerciáveis implica aumento da demanda por bens comerciáveis e redução da produção doméstica destes. Assim, a apreciação do câmbio real reduz a disponibilidade doméstica de bens de capital, entendida como a soma da produção doméstica de bens de capital destinada ao mercado interno e das importações destes bens até o ponto onde o saldo em transações correntes se equilibra. Após a apreciação da taxa de câmbio real torna-se necessário aumentar o volume de importação líquida (de bens de capital) de modo a viabilizar dado volume de investimento, deteriorando-se o saldo em transações correntes. Então, a parcela do investimento total que corresponde à demanda de bens de capital satisfeita através da compra destes bens no mercado interno e da importação de bens de capital até o ponto onde o saldo em transações correntes se equilibra, se reduz após a apreciação da taxa de câmbio real, ensejando na mesma medida um menor volume de poupança nacional no âmbito do circuito F-I-S-F.

Portanto, não se trata, neste caso, de insuficiência de poupança nacional em relação a uma dada taxa de investimento. Partindo de um dado nível do investimento doméstico, quando há apreciação da taxa de câmbio real, surgem déficits em conta corrente estimulando a formação de poupança no resto do mundo a partir do investimento doméstico, enquanto o estímulo sobre a renda doméstica

\footnotetext{
${ }^{19}$ Porém, conforme Keynes (1988a), em economias monetárias o pleno emprego é apenas uma entre inúmeras possibilidades de equilíbrio macroeconômico. Em geral, o nível do produto de equilíbrio em economias monetárias encontra-se aquém do nível de pleno emprego. Este argumento é corroborado na teoria microeconômica não convencional. Possas (1987), Labini (1962), etc., sustentam que faz parte da estratégia das empresas trabalhar, em regra, com capacidade produtiva ociosa. ${ }^{20}$ Há na abordagem pós-keynesiana vários canais através dos quais o déficit público afeta o investimento e que não são objeto de estudo neste trabalho. Trata-se da relação entre: déficit público e demanda efetiva, déficit público e melhora ou deterioração das expectativas dos agentes, déficit público e oferta de finance nacional e internacional, etc.
} 
e sobre a poupança doméstica será reduzido. Este efeito do investimento sobre a formação da poupança nacional no contexto de apreciação da taxa de câmbio real pode ser constatado a partir da análise das Situações 1 e 2, anteriormente apresentadas.

Segundo Resende (2005), para que o resultado fiscal do governo provoque necessariamente uma mudança de preços relativos, a economia em análise deve operar a pleno emprego e com taxa de câmbio fixa num contexto de ausência de crowding out e de Equivalência Ricardiana. Vamos considerar que este é o caso do país Z. Supõe-se, também, que $\mathrm{W}$ e $\mathrm{Z}$ apresentam inicialmente saldo equilibrado em conta corrente. Considera-se que $\mathrm{W}$ e $\mathrm{Z}$ são os únicos países existentes e que o regime cambial de $W$ também é o de taxas fixas.

$\mathrm{O}$ déficit público na economia $\mathrm{Z}$ induz a apreciação da sua taxa de câmbio real, provocando um déficit em conta corrente, pois se supõe constante o volume de investimentos em $Z$ e em W. Surge, então, um excesso de demanda por bens comerciáveis no país $Z$, inclusive por BK, satisfeito por meio de importações. ${ }^{21}$ Se W também opera a pleno emprego, haverá excesso da demanda mundial de bens comerciáveis em relação à oferta mundial, gerando aumento de preço desses bens e, então, depreciação da taxa de câmbio real em W. Esta mudança de preços relativos em $\mathrm{W}$ amplia sua produção potencial de bens comerciáveis. ${ }^{22}$

Entretanto, se há capacidade ociosa na economia W, suas exportações serão ampliadas, satisfazendo o excesso de demanda de bens comerciáveis do país $Z$, sem haver necessariamente mudança de preços relativos. Assim, supondo que após a apreciação da taxa de câmbio real em $\mathrm{Z}$ o volume de investimento não se altera, nem no país $W$, nem no país $Z$, tal apreciação cambial resultará em alterações no saldo em conta corrente de ambas as economias. ${ }^{23}$

\footnotetext{
${ }^{21}$ Parcela da produção doméstica de bens comerciáveis, inclusive BK, torna-se economicamente inviável após a apreciação da taxa de câmbio real, ao mesmo tempo em que há uma substituição da demanda de bens não-comerciáveis pela de bens comerciáveis, conforme enfatizado anteriormente.

${ }^{22} \mathrm{Em} \mathrm{W}$, a depreciação da taxa de câmbio real torna economicamente viável parcela do estoque de capital destinado a produzir bens comerciáveis, permitindo a expansão da produção de BK e de BCS sem a necessidade de nova formação de capital fixo. Ou seja, na Situação 2 descrita na subseção 3.2, a produção em W de BK destinados à exportação gera uma renda que induzirá um novo consumo; porém, a depreciação cambial numa economia que já operava a pleno emprego viabiliza o aumento da produção doméstica de BCS. Note, ainda, que o aumento da oferta de bens comerciáveis no resto do mundo não permite que o aumento de preços dos mesmos na economia $\mathrm{Z}$ anule completamente a mudança de preços relativos inicialmente verificada no país $\mathrm{Z}$ em favor dos bens não comerciáveis.

${ }^{23}$ Se o regime cambial de $\mathrm{W}$ fosse o de taxas flexíveis, o aumento da demanda de importação do país $\mathrm{Z}$ implicaria aumento da oferta de divisas externas em W e apreciação de suas taxas de câmbio nominal e real. Portanto, surgiria no mundo um excesso de demanda por bens comerciáveis em relação à oferta dos mesmos, provocando aumento de preços desses bens e revertendo a apreciação da taxa de câmbio real tanto em $\mathrm{Z}$ quanto em $\mathrm{W}$. Assim, o déficit público em $\mathrm{Z}$ teria provocado apenas inflação. $\mathrm{O}$ aumento de preços em $\mathrm{Z}$ atuaria como mecanismo de redução da participação do setor privado no produto real em favor do aumento da participação do setor público. Isto não provoca, necessariamente,
} 
Até ocorrerem alterações nas taxas de câmbio, o saldo em conta corrente era equilibrado em W e em Z. Esta era a Situação 1, anteriormente analisada. Após essas mudanças, quando passamos para a Situação 2, verifica-se um déficit e um superávit em conta corrente no país $\mathrm{Z}$ e no país $\mathrm{W}$, respectivamente. A apreciação da taxa de câmbio real reduz a disponibilidade doméstica de capital em $\mathrm{Z}$ isto é, reduz o montante formado pela soma da produção doméstica de BK destinada ao mercado interno e das importações destes bens até o ponto onde o saldo em transações correntes se equilibra. Assim, mantido o mesmo nível de investimento, haverá um déficit em conta corrente nesse país.

Na Situação 1 não havia poupança no país W, pois a renda não consumida internamente era usada para importar bens de consumo. Em W, a Situação 2 surge quando sua exportação de BK eleva-se e sua importação de BCS cai a zero, após ocorrer apreciação da taxa de câmbio real em $\mathrm{Z}$ decorrente, por exemplo, do déficit público neste país. A produção de BK para exportação enseja aumento da renda em W e, via efeito multiplicador, surge uma poupança cuja contrapartida são as exportações de BK em valor igual ao superávit em conta corrente de W. A mudança de preços relativos verificada inicialmente na economia $\mathrm{Z}$ estimulou o aumento da produção de BK em W, mas, conforme analisado anteriormente, tal tarefa exigiu inicialmente um finance no mercado doméstico, liquidado a partir da poupança que surgiu como resíduo do crescimento da renda. Em última instância, a apreciação da taxa de câmbio real em $\mathrm{Z}$ estimulou a formação de poupança em W, ao mesmo tempo em que a produção de BK para exportação neste país (que corresponde ao investimento na economia Z) não necessitou de uma poupança prévia, mas, sim, de finance.

$\mathrm{Na}$ situação 1 , a poupança verificada na economia $Z$ resultava da produção de BCS para exportação, apresentando o mesmo valor das importações de BK, de modo que a poupança nacional era igual ao investimento e o saldo em conta corrente era nulo. Após a apreciação da taxa de câmbio real, parcela da produção de bens comerciáveis torna-se economicamente inviável, enquanto a demanda por estes bens aumenta. Para simplificar o raciocínio, mas sem comprometer as conclusões da análise, digamos que toda exportação da economia $\mathrm{Z}$ torna-se nula após a apreciação cambial. Mantendo-se o mesmo nível de investimento em $\mathrm{Z}$, as importações de BK aumentarão, realizadas por meio do finance no sistema financeiro internacional, conforme descrito na Situação 2.

Portanto, após a apreciação cambial em Z, este país e o país W passam da Situação 1 para a Situação 2, e o estímulo do investimento na economia $Z$ para a formação de poupança se transfere parcialmente do país $Z$ para o país W. No país $\mathrm{Z}$ o excesso de investimento sobre a poupança resulta em déficit em conta corrente.

queda do volume de investimento e de poupança nacional. Portanto, quando prevalece o pleno emprego nas economias, o caso relevante a ser analisado é aquele em que ambas as economias operam sob regime de taxas de câmbio fixas. 
Em suma, quando o déficit público provoca uma mudança de preços relativos verifica-se um deslocamento (parcial) da demanda por bens de investimento do mercado doméstico para o mercado externo. Por conseguinte, parcela do estímulo do investimento para a formação de poupança se transfere para o resto do mundo, e, ex-post, o investimento permanece sendo igual à soma da poupança nacional e da absorção de poupança externa.

\section{CONCLUSÕES}

O objetivo principal deste estudo foi avaliar se as características do circuito F-I-S-F permanecem válidas para economias abertas, em especial se o investimento continua precedendo a poupança após a abertura da economia monetária. Constatou-se a validade deste circuito para economia abertas.

Uma segunda questão também foi estudada, no âmbito do debate referente à precedência do investimento em relação à poupança: trata-se do argumento sobre a insuficiência (ou restrição) de poupança nacional em relação ao investimento, provocada pelo déficit público.

Conforme alguns autores, tais como Giambiagi \& Amadeo (1990), Garcia (1997), Garcia \& Giambiagi (1997), Giambiagi (2002), no pleno emprego não haveria recursos reais disponíveis que permitissem absorver um aumento do gasto público (líquido). Segundo estes autores, tal absorção só seria possível mediante uma redução do consumo e/ou do investimento. Assim, a elevação da taxa de investimento implicaria, necessariamente, aumento de importações de BK sem a contrapartida do aumento de exportações, e a restrição ao crescimento econômico seria de poupança nacional. Isto nos remeteu ao argumento pós-keynesiano, segundo o qual é o investimento que antecede a poupança em economias monetárias, e, não, o contrário. Sendo assim, a restrição ao crescimento econômico não poderia ser de poupança.

Ademais, na economia fechada o déficit público não reduz a produção potencial de bens de investimento uma vez que BK que produzem BK não podem milagrosamente se metamorfosear em máquinas e equipamentos produtores de BCS para atender às demandas de um governo perdulário. ${ }^{24}$ Isto é, o déficit público numa economia fechada não pode reduzir o limite físico superior existente à ampliação da produção doméstica de bens de investimento.

Porém, na economia aberta, se o déficit público provocar a apreciação da taxa de câmbio real, embora aquele não cause necessariamente esta apreciação,

\footnotetext{
${ }^{24}$ A indicação de política econômica derivada a partir do referencial teórico pós-keynesiano não é por um contínuo desequilíbrio fiscal. Isto seria nocivo para o investimento no contexto da formação de expectativas a longo prazo. Segundo este referencial, o governo deveria ter dois orçamentos: o orçamento corrente e o de capital. O primeiro deve ser sempre equilibrado, enquanto o segundo teria o papel de suavizar o ciclo econômico, devendo ser intertemporalmente equilibrado. Sobre este ponto, ver Carvalho (1992a, cap.12).
} 
a disponibilidade doméstica de capital na economia - entendida como a soma da produção doméstica de bens de capital destinada ao mercado interno e das importações destes bens até o ponto onde o saldo em transações correntes se equilibra - será reduzida. Mas, na ótica pós-keynesiana, isto não quer dizer uma restrição de poupança nacional em relação ao investimento. O que ocorre é tão somente que, no país onde houve apreciação cambial, há uma transferência para o resto do mundo de parcela do estímulo dado pelo investimento doméstico para a formação de poupança.

Deste modo, o investimento permanece antecedendo a poupança, mesmo quando a economia opera a pleno emprego, ou seja, o circuito pós-keynesiano Finance-Investimento-Poupança-Funding permanece válido em qualquer situação. Porém, parcela da poupança estimulada pelo investimento forma-se fora do país onde houve apreciação da taxa de câmbio real.

Por fim, haveria na ótica pós-keynesiana uma restrição física (restrição de disponibilidade de recursos reais) ao aumento do investimento quando a economia opera a pleno emprego? Quando o aumento da absorção doméstica decorrente do aumento do investimento induz a apreciação da taxa de câmbio real, o saldo em conta corrente deteriora-se e parte do estímulo do investimento para a formação da poupança se transfere para os parceiros comerciais do país onde o investimento está sendo efetivado. Neste caso, a restrição ao investimento que poderia surgir seria de recursos externos (restrição externa), e, não, de poupança.

Porém, se a taxa de câmbio real não se apreciar, o aumento do investimento resultará em inflação, o que poderá desestimular o próprio investimento (aumento do preço de oferta dos BK) e/ou reduzir a participação de algum setor da economia no produto agregado em favor do aumento da participação dos investidores.

\section{REFERÊNCIAS BIBLIOGRÁFICAS}

Amadeo, Edward (1995) "Nem câmbio nem ajuste fiscal”. Revista de Economia Política, 15, 2 (58): 136-138. Disponível em: http://www.rep.org.br/pdf/58-10.pdf

Amado, Adriana M. (2000) "Limites monetários ao crescimento: Keynes e a não neutralidade da moeda". Ensaios FEE 21(1): 44-82.

Baharumshah, Ahmad Z.; Lau, Evan e Khalid, Ahmed M. (2005) "Testing twin deficits hypothesis: using VARs and variance decomposition". Economics Working Paper Archive at WUSTL. Disponível em: http://ideas.repec.org/p/wpa/wuwpif/0504001.html\#provider

Bahmani-Oskooee, Mohsen (1995) "The long-run determinants of US trade balance revisited". Journal of Post Keynesian Economics 17(3): 457-465.

Cardim de Carvalho, Fernando J. (1992a) Mr Keynes and the Post Keynesians: Principles of Macroeconomics for a Monetary Production Economy. Londres: Edward Elgar.

. (1992b) "Moeda, produção e acumulação: uma perspectiva pós-keynesiana”. In: Silva, Maria Luiza F. (org), Moedas e Produção:Teorias Comparadas. Brasília: ed. UnB.

. (1993) "Sobre a endogenia da oferta de moeda: réplica ao professor Nogueira da Costa". Revista de Economia Politica, 13, 3 (51): 114-121. Disponível em: http://www.rep.org.br/pdf/518.pdf

Crocco, Marco A. (2002) “The concept or degrees of uncertainty in Keynes, Shakle, and Davidson”. Nova Economia 12(2): 11-28.

Davidson, Paul (1992) International Money and the Real World. Londres: Macmillan (2 edição). 
. Post Keynesian macroeconomic theory: a Foundation for Successful Economic Policies for the Twenty-First Century. Cambridge: Cambridge University Press.

De Paula, Luis Fernando R. (1999) “Teoria da firma bancária”. In: Lima, G. T., Sicsú, J. e De Paula, L. F. R. Macroeconomia Moderna: Keynes e a Economia Contemporânea. Rio de Janeiro: Campus.

Feijó, Carmen A. et alii (2001) ContabilidadeSocial: O Novo Sistema de Contas Nacionais do Brasil. Rio de Janeiro: Campus.

Feldstein, Martin (1992) “The budget and trade deficits aren't really twins”. NBER Working Paper 3966.

Garcia, Márcio G. P. (1997) “Macroeconomia prática”. Gazeta Mercantil, 16/04.

Garcia, Márcio G. P. e Giambiagi, Fábio (1997) "Poupança e crescimento econômico". Gazeta Mercantil, 2/06.

Giambiagi, Fábio (1988) "Taxa de poupança, restrições ao crescimento e política econômica: uma abordagem integrada”. Texto para Discussão 169. Rio de Janeiro: UFRJ/IEI.

. (2002) "Restrições ao crescimento da economia brasileira: uma visão de longo prazo". Revista do BNDES 9(17).

Giambiagi, Fábio e Amadeo, Edward (1990) "Taxa de poupança e política econômica: notas sobre as possibilidades de crescimento numa economia com restrições". Revista de Economia Política, 10, 1 (37): 75-90. Disponível em: http://www.rep.org.br/pdf/37-4.pdf

Kandir, Antonio (1989) A Dinâmica da Inflação: Uma Análise das Relações entre Inflação,Fragilidade Financeira do Setor Público, Expectativas e Margens de Lucro. São Paulo: Nobel.

Keynes, John M. (1988a) A Teoria Geral do Emprego, do Juro e da Moeda. São Paulo: Nova Cultural. . (1988b) "Teorias alternativas da taxa de juros". In: Clássicos da literatura econômica. Rio de Janeiro: IPEA/INPES.

. (1988c) "A teoria ex ante da taxa de juros". In: Clássicos da literatura econômica. Rio de Janeiro: IPEA/INPES.

Kregel, Jan (1998) The Past and the Future of Banks. Quaderni di Ricerche 21. Roma: Bancaria.

Krugman, Paul R. (1992) Currencies and Crises. Cambridge: MIT Press.

Minsky, Hyman P. (1986) Stabilizing and Unstable Economy. New Haven: Yale University Press.

Possas, Mario L. (1987) Estruturas de Mercado em Oligopólio. São Paulo: Hucitec.

Pastore, Affonso C. e Pinotti, Maria C. (1995) "Taxa cambial real e os saldos comerciais". Revista de Economia Politica, 15, 2, (58): 138-145. Disponível em: http://www.rep.org.br/pdf/58-10.pdf

Pereira, Thiago R. (1999) Endividamento Externo e o AjusteFinanceiro da Grande Empresa Industrial nosAnos Noventa. Dissertação de mestrado. Campinas: Instituto de Economia da Unicamp.

Resende, André L. (1995) “O México e o câmbio: tequila, câmbio e o velho cinismo". Revista de Economia Política 15, 2 (58): 134-136. Disponível em: http://www.rep.org.br/pdf/58-10.pdf

RESENDE, Marco F. C. (2003) Inserção Internacional, Arranjos Financeiros e Crescimento da Economia Brasileira. Tese de doutoramento. Brasília: UnB.

. (2005) "Déficits gêmeos e poupança nacional: abordagem convencional e pós-keynesiana". Anais do XXXIII Encontro Nacional de Economia. Natal: ANPEC. Disponível em: http://www.anpec.org.br/encontro_2005.htm

ROSENSWEIG, Jeffrey A. e TALLMAN, Ellis W. (1993) "Fiscal policy and trade adjustment: are the deficits really twins?". Economic Inquiry 31: 580-594.

Silos-Labini, Paolo (1962) Oligopoly and Technical Progress. Cambridge: Harvard University Press.

Studart, Rogerio (1995) Investment Finance in Economic Development. London: Routledge.

Tavares, Maria C.; Assis, J. C. e Teixeira, A. (1982) "A questão da poupança: desfazendo confusões". In: Tavares, Maria C. e David, Maurício D. (org) A Economia Política da Crise. Rio de Janeiro: Vozes.

Vamvoukas, George A. (1999) “The twin deficits phenomenon: evidence from Greece”. Applied Economics 31(9): 1093-1100.

Winckler, Georg; Scharler, Johann e Kaufmann, Sylvia (1999) “The Austrian current account deficit: Driven by twin deficits or by intertemporal expenditure allocation?”. University of Vienna, Working Paper 9903. 